\title{
Assessing the Impact of an Interactive Mobile Game on Tobacco-Related Attitudes and Beliefs: The Truth Campaign's "Flavor Monsters"
}

\author{
Jessica M. Rath, PhD, MPH, ${ }^{1,2}$ Valerie Williams, MA, MS, Rebecca Rubenstein, BA, ${ }^{3}$ \\ Lexi Smith, MSPH, and Donna Vallone, $\mathrm{PhD}, \mathrm{MPH}^{1,2}$
}

\begin{abstract}
Given that over 97 percent of American teens play videogames, it is not surprising that many "games for health" target youth. Although tobacco use is the leading cause of preventable death in the United States, few digital games focus on preventing this behavior. The aims of this study were twofold: (1) to determine if youth will play a game with tobacco-related information and themes and (2) to explain the relationship between the truth ${ }^{\circledR}$ (Legacy, Washington, DC) campaign's "Flavor Monsters" gameplay and shifts in game-related tobacco knowledge, attitudes, and beliefs. First, two versions of the game, with different amounts of tobacco-related content, were developed to examine the influence of tobacco-related content on player engagement, length of play, awareness of the truth brand, and receptivity to the game. No statistically significant differences were found for engagement $(P=0.81)$, length of play $(P=0.10)$, or awareness of the truth brand $(P=0.67)$. Using an online survey through a preexisting online panel of 13-24 year olds, a longitudinal $(n=693)$ design was used whereby exposure to messages varied naturally over time. Because of the large number of anti-tobacco industry attitude questions, we created an Anti-Tobacco Industry (ATI) Index based on the results of a factor analysis. Although gameplay was not a predictor of lower levels of intention to smoke, level mastered was a significant positive predictor of ATI Index attitudes score at 3 months, controlling for baseline ATI Index score, age, gender, and ever cigarette use $(P=0.002)$. Longitudinal findings indicate a cumulative and enduring effect, suggesting that antitobacco content can be successfully integrated within a mobile game to help increase anti-tobacco attitudes.
\end{abstract}

\section{Introduction}

$\mathbf{I}$ NTERACTIVE DIGITAL GAMES have become an increasingly popular strategy for e-health interventions. ${ }^{1,2}$ In the past decade, game developers and public health practitioners have created digital games promoting a range of healthy behaviors, including vigorous physical activity, ${ }^{3-6}$ cancer treatment adherence, ${ }^{7}$ human immunodeficiency virus infection prevention, ${ }^{8}$ healthy eating, ${ }^{9}$ and building healthy relationships. ${ }^{10}$ This category of games with a social purpose has been dubbed "serious games" or "games for health." It is not surprising that many of these games with a health focus target youth because over 97 percent of American teens play videogames, and close to a third of all teens play at least once a day. ${ }^{11}$ Digital games have migrated from consoles and desktop computers to mobile platforms as mobile device use has in- creased among youth and younger adults. ${ }^{6,8,9,12}$ More than ever before, health-related games on mobile devices facilitate exposure to health information and thus may have potential to help shape attitudes and beliefs about healthy behavior.

Although tobacco use is the leading cause of preventable death in the United States, ${ }^{13,14}$ few digital games focus on preventing or reducing this behavior. In 1994, the U.S. Agency for Healthcare Research and Quality created a console-based tobacco prevention game for adolescents called "Rex Ronan: Experimental Surgeon." 15 For adult smokers, digital games such as "Lit 2 Quit,"16 "Kwit,"17 a board game named "Pick-Klop,"18 and a virtual reality experiment ${ }^{19}$ offer a gaming experience to reduce or stop smoking. However, there have been no published data in the United States demonstrating the impact of gaming interventions on changes in knowledge and attitudes related to lower tobacco

Departments of ${ }^{1}$ Evaluation Science and Research and ${ }^{3}$ Marketing, Legacy, Washington, D.C.

${ }^{2}$ Department of Health, Behavior and Society, Johns Hopkins Bloomberg School of Public Health, Baltimore, Maryland.

(C) The Author(s) 2015; Published by Mary Ann Liebert, Inc. This Open Access article is distributed under the terms of the Creative Commons Attribution Noncommercial License (http://creativecommons.org/licenses/by-nc/4.0/) which permits any noncommercial use, distribution, and reproduction in any medium, provided the original author(s) and the source are credited. 
Table 1. Characteristics of "Flavor Monsters",

General game characteristics

Health topics addressed

Target age group

Other targeted group

characteristics

Short description of game

Target players

Guiding theory or behavior change theory

Intended health behavior change

Knowledge elements to be learned

Behavior change procedures used

Clinical or parental support needed

Data shared with parent or clinician

Type of game

Story

Synopsis

How the story relates to targeted behavior change

Game components

Player's game goal/objective(s)
Tobacco use, specifically flavored tobacco use

13-24 year olds

Open-to-smoking, active mobile gamers

"Flavor Monsters" is a free mobile game application set in an alternate universe where evil fantasy creatures that represent tobacco flavors like Menthol and Honey try to destroy the world. From the vantage point of an airship circling the city, the player has total visibility of the play area and the different points from which the Flavor Monsters are spawning. The game features six levels of play or "battle zones," each representing a U.S. city, which are progressively more challenging as players are confronted with different types of Flavor Monsters. Flavor Monsters attack, intensify, or regenerate while players attack the monsters with various tools. To aid players in defeating the Flavor Monsters throughout the game, a teenage character, Kelsey, appears within the game and provides gameplaying tips, which also include tobacco-related facts. Mr. White is a mysterious character who provides helpful information to Kelsey about Flavor Monsters. Players can pay to upgrade tools. In the final extraction chamber, Mr. White, who has appeared as a helpful guide throughout the game, appears unexpectedly, and it is revealed that Mr. White represents menthol, the only flavor in cigarettes not banned by the Family Smoking Prevention and Tobacco Control Act. Mr. White (Menthol) must be defeated to win the game. The Flavor Monsters are designed as deadly attackers, and tobacco-related facts are provided throughout the game, so that players can develop an understanding of the deadly nature of tobacco products. Thus, the game is a metaphor for defeating the tobacco industry.

Individual

Theory of Planned Behavior-The game focuses on changing knowledge, beliefs, and attitudes around tobacco use and the industry to eventually influence intentions to not use flavored tobacco.

Tobacco use among 13-24 year olds, specifically flavored tobacco use

Facts about tobacco use and the tobacco industry, for example, "In 1972, a tobacco company considered adding honey to cigarettes because teenagers like sweet products."

Vicarious learning: players are more likely to retain the anti-tobacco message by playing the game because the game is a metaphor for the tactics of the tobacco industry; players are part of the message, not just exposed to the message. The graphics, style, music, and language of "Flavor Monsters" are also designed to evoke emotion in players, which contributes to attitude and beliefs changes related to tobacco. No

No

Tower defense, action, adventure, strategy, educational, causal, aerial shooter, actionbased tap game

Seemingly cute little Flavor Monsters are invading America. They are attacking cities and must be stopped. You are deployed to a massive airship circling the city tasked with protecting one important landmark in each city. With various game tools at your disposal, you battle hordes of oncoming Flavor Monsters before they take over the key city landmarks. After you capture enough monsters to meet your Flavor Monster quota of 1200 deaths per day (the same number of Americans who die daily of tobacco-related illness), the Level Boss appears, and you must damage him to a certain degree to trigger the boss extraction minigame where you use the phone's shake, tap, and drag gestures to get key information about the Flavor Monsters' plans and the overall game story. During your six-mission campaign, you are assisted by a mentor character named Kelsey who gives you critical mission tips and advice along the way to discovering who these Flavor Monsters are and why they are attacking. He also has a connection with a mysterious character named Mr. White who provides Kelsey with information about Flavor Monsters. Ultimately, the player finds out he's been duped, and the game's final boss is actually Mr. White.

When Kelsey provides critical mission tips, he always relates them to a tobacco fact designed to change player attitudes and beliefs about tobacco.

Complete six levels of gameplay by defeating 1200 monsters in each city and defeating each level boss. 
TABle 1 (CONTINUED)

\begin{tabular}{|c|c|}
\hline Characteristic & Description \\
\hline Rules & $\begin{array}{l}\text { Utilize various tools and items to capture hordes of Flavor Monsters by using touch } \\
\text { control (tap) attacks. Players start with one basic tool and are introduced to other } \\
\text { tools as the levels unfold and the enemies get stronger. When a player taps on Flavor } \\
\text { Monsters to target, they will disappear. Monsters "poof" and then are captured, } \\
\text { causing an onscreen counter to click off each time one is captured. Bosses appear } \\
\text { when a 1200-count of Flavor Monsters is defeated, and the player must knock the } \\
\text { Level Boss down to a certain health level before launching the extraction minigame. } \\
\text { To win the game, players must defeat the final boss monster at the end. }\end{array}$ \\
\hline \multicolumn{2}{|l|}{ Game mechanic(s) } \\
\hline $\begin{array}{l}\text { Procedures to generalize or } \\
\text { transfer what is learned } \\
\text { in the game to outside } \\
\text { the game }\end{array}$ & $\begin{array}{l}\text { Procedural rhetoric or the idea that the player of the game is part of the message of the } \\
\text { game. This is a unique contribution to the overall mission of the truth campaign, } \\
\text { which clearly distinguishes truth gaming from a more traditional 30-second television } \\
\text { ad. Both can educate the audience in different ways toward the same goal- to build a } \\
\text { world where young people reject tobacco. }\end{array}$ \\
\hline \multicolumn{2}{|r|}{ 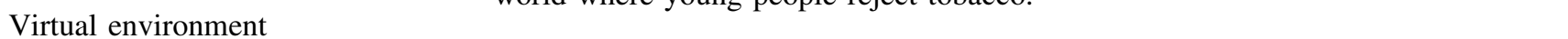 } \\
\hline Setting & $\begin{array}{l}\text { During the introduction, the player is introduced to a map of the United States and the } \\
\text { different regions under attack. The six level locations are as follows: } \\
\text { 1. Sunnyland } \\
\text { 2. Pacific Northwest } \\
\text { 3. Heartland } \\
\text { 4. Hot South } \\
\text { 5. Metropolis } \\
\text { 6. Capital } \\
\text { Each city has a unique landmark that the player will be protecting from the Flavor } \\
\text { Monsters. If too many Flavor Monsters reach the landmark, the player loses the level } \\
\text { and can retry from the game over screen. From the airship, players are focused on } \\
\text { capturing Flavor Monsters, tool selection, and managing the overall battlefield. }\end{array}$ \\
\hline \multicolumn{2}{|r|}{ 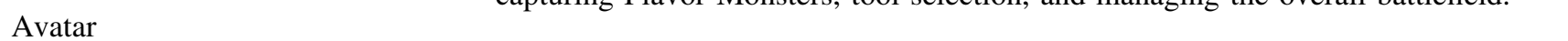 } \\
\hline Characteristics & NA \\
\hline $\begin{array}{l}\text { Game platform needed to } \\
\text { play game }\end{array}$ & iOs and Android smartphones and tablets \\
\hline Sensors used & \\
\hline Estimated play time & Roughly 4.5 hours total over a course of several sessions \\
\hline
\end{tabular}

NA, not applicable.

use. In China, there is one example of a tobacco use prevention game that increased negative attitudes toward tobacco use after players completed one round of the game. ${ }^{20}$ Because the majority of smokers first experiment with cigarettes by 18 years of age $^{21}$ and progression to regular smoking often occurs during young adulthood, ${ }^{22}$ youth- and young adult-focused interventions are critical to prevent the disease and death caused by tobacco use.

Since 2000, the $\operatorname{truth}^{\circledR}$ (Legacy, Washington, DC) campaign, the most successful and one of the largest national youth smoking prevention campaigns, has used mass media messages to expose youth and young adults to the facts about the health and social consequences of tobacco. ${ }^{23}$ As referenced in other studies, truth embraces a branded strategy to increase anti-tobacco industry attitudes in an effort to reduce tobacco use. ${ }^{24,25}$ The truth campaign's "Flavor Monster" game was created using this same strategy. Given the significant penetration of digital gaming among their target audience, the truth campaign developed and released nearly two dozen branded flash games for desktop and three original mobile platform games between 2005 and 2013. ${ }^{26}$ In August 2012 , the truth campaign released its second original mobile game, "Flavor Monsters." 27,28 To increase reach and utilization, the truth campaign promoted the launch of "Flavor Monsters" through multiple media channels, including television, cinema, out-of-home, digital, mobile, and social media channels as part of a 2-year grant awarded by the Centers for Disease Control and Prevention.

The major challenge for developers of games designed to influence behavior is operationalizing the delicate balance of simultaneously entertaining and educating. Buday et al. ${ }^{29}$ suggested that serious games, although often characterized as boring, need to avoid alienating players and strive for likeability. Thus, the goal of "Flavor Monsters" was to sufficiently engage young people to foster continued play while exposing players to sufficient levels of anti-tobacco messaging. The aims of this study were twofold: (1) to determine if youth will play a game with tobacco-related content and (2) to explain the relationship between "Flavor Monsters" gameplay and shifts in gamerelated tobacco knowledge, attitudes, and beliefs. In the first phase of the study, two versions of the game were developed to examine the influence of tobacco-related content on player engagement, length of play, awareness of the truth brand, and receptivity to the game. The second phase of the study used a longitudinal study design of players whereby gameplay, and thus exposure to messages, varied naturally over time.

\section{Materials and Methods}

\section{The game: "Flavor Monsters"}

The tobacco-related content within "Flavor Monsters" was inspired by the fact that tobacco companies in the United 
States, although banned from selling flavored cigarettes, are not prohibited from selling other flavored tobacco products in over 45 candy flavors. To bring this fact to life, the game takes place in an alternate universe where evil fantasy creatures representing actual tobacco flavors like Sour Apple, Cherry and Honey try to destroy the world.

The game, which was designed for 13-24 year olds, features six levels of play that are progressively more challenging as players are confronted with different types of "Flavor Monsters" that attack, intensify, or regenerate (Table 1). To aid players throughout the game, an animated teenage character, Kelsey, appears within the game and provides gameplaying tips. As gameplay progresses, Kelsey narrates the story and highlights facts about the tobacco industry and its products. Examples of facts include "As late as 1999, tobacco companies placed in-store advertising signage at a child's eye level" and "In 1984, a tobacco company called younger adult smokers replacement smokers." Mr. White, the "Menthol" Flavor Monster, represents the only flavor in cigarettes not banned by the Family Smoking Prevention and Tobacco Control Act. Game rules dictate that Mr. White must be defeated in order to win the game, much like banning menthol flavoring would be a "win" for tobacco control.

To facilitate broad participation, "Flavor Monsters" was designed for both iOS (Apple, Cupertino, CA) and Android $^{\mathrm{TM}}$ (Google, Mountain View, CA) platforms and optimized for smartphones and tablets. To date, there have been 1.4 million downloads of the game.

\section{Testing game content integration}

The initial phase of the study focused on determining whether differences in the delivery and amount of tobaccorelated information influenced length of play, engagement, liking, and awareness of the truth brand. Thus, two versions of the game were developed: version A (Fig. 1) included a clearer presentation of facts related to the use of flavors by the tobacco industry, and version B (Fig. 2) did not include direct references to the tobacco industry. Study participants 13-24 years of age with access to a mobile device were recruited from an online panel from June 8 through October 12, 2012. Respondents completed a pretest survey, were randomly assigned to one version of the game, and then were asked to complete a posttest survey. Data indicated that clear messaging content of tobacco-related information did not negatively impact length of play, engagement, receptivity, or awareness of the truth brand. No statistically significant differences were found for engagement (version $\mathrm{A}$, mean score $=28.0$; version $\mathrm{B}$, mean score $=27.6 ; P=0.81$ ), length of play $(P=0.10)$, or awareness of the truth brand $(P=0.67)$. Thus, version A, with higher levels of tobacco-related information, was selected for the next phase of the study. This phase of the study was approved by the Independent Institutional Review Board.

\section{Evaluating the impact of gameplay}

We used a single-group repeated-measures design to evaluate the impact of gameplay over time. Data were collected via the Harris Interactive Service Bureau using the Harris Poll Online panel of cooperative respondents. All participants meeting inclusion criteria completed a recruitment survey with questions on demographics, general gameplay behaviors, and measures of tobacco attitudes, beliefs, and behaviors. From this online panel, a sample of youth and young adults was recruited meeting the following inclusion criteria: (1) 13-24 years of age; (2) reported access to an $\mathrm{iOS}$ or Android mobile device; (3) played any digital game on that device in the past 6 months; and (4) agreed to download "Flavor Monsters" and complete three follow-up surveys. A baseline sample of 2,623 participants was collected with

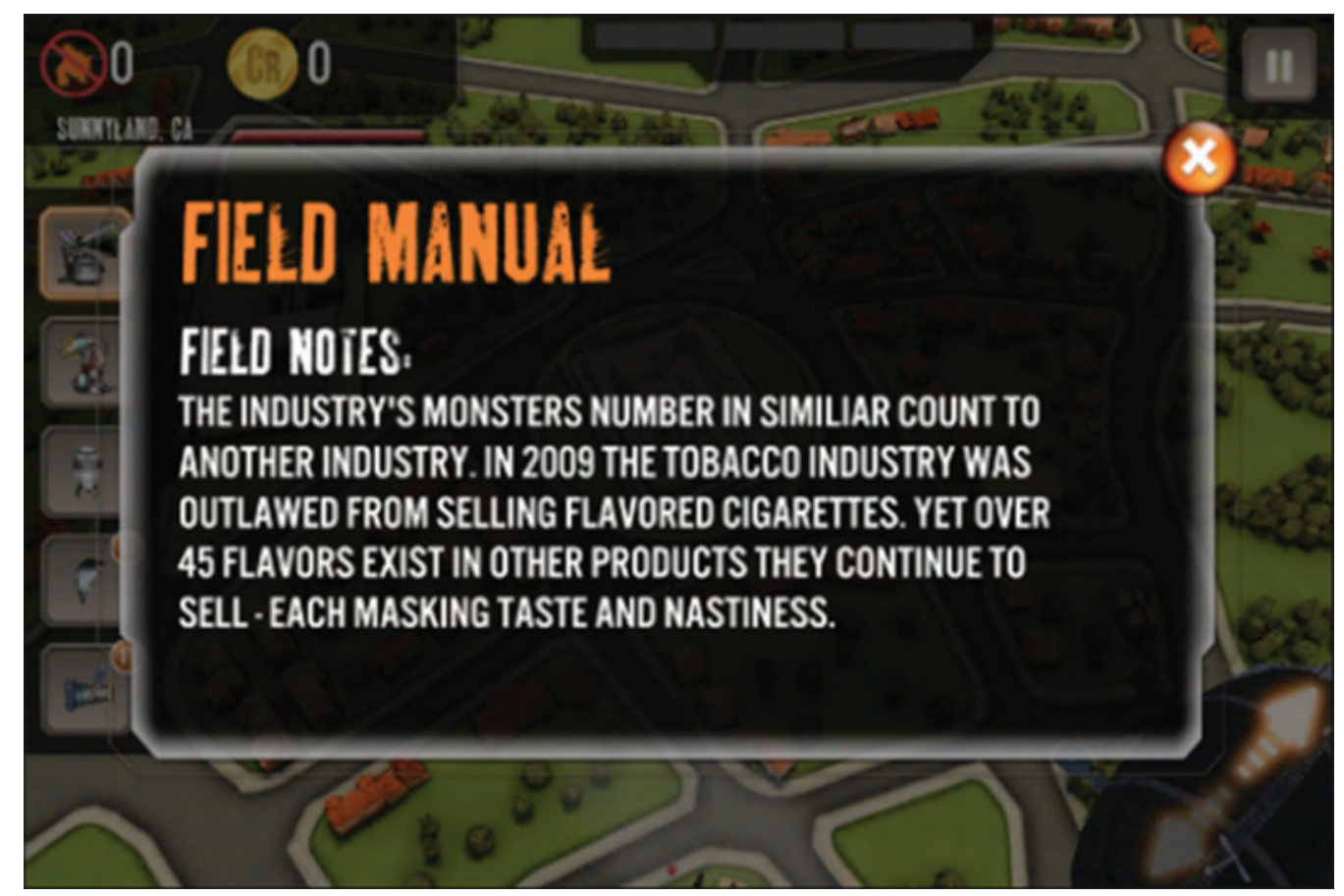

FIG. 1. Screenshot of "Flavor Monsters" Version A. (Color images available at www.liebertonline.com/g4h) 


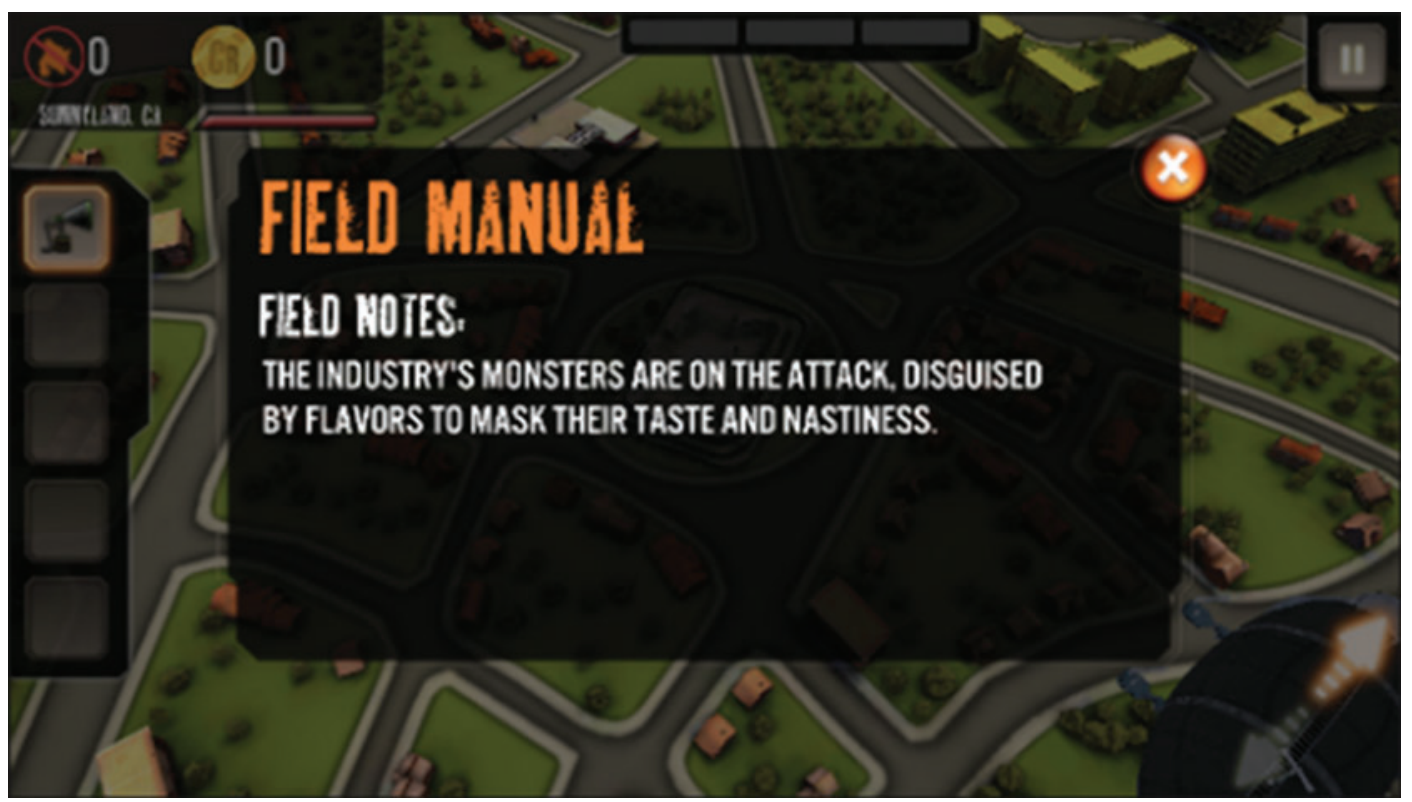

FIG. 2. Screenshot of "Flavor Monsters" Version B. (Color images available at www.liebertonline.com/g4h)

follow-up data obtained 1 week $(n=1389), 1$ month $(n=$ $1223)$, and 3 months $(n=1003)$ after recruitment. In total, 689 participants completed all three follow-up surveys (weighted $n=693$ ). The online survey included items to assess game engagement, level achieved in the game, and tobacco-related knowledge, attitudes, beliefs, and behaviors. This phase of the study was approved by Chesapeake Institutional Review Board.

\section{Measures}

Background variables included age, gender, and race/ ethnicity. Respondents' education level was dichotomized as completed some high school or less and some college or more. Parental highest educational attainment was categorized as less than high school, high school graduate, some college/Associates degree, and college graduate or higher. Frequency of overall gameplay was assessed using the following item: "How many different games on your phone or tablet do you play in a typical week?" Answer choices included "1-5," "6-10," "11-20," and "over 20."

Level of mastery was measured using self-report items with screenshots from each of the levels to assist in recall. Level 1 included the majority of tobacco-related information to help ensure that players who did not complete the game were still exposed to a majority of the facts.

In total, seven tobacco-related facts were in Levels 1 and 2 , and five facts were included in Levels 3-8. Thus, we expected to see an association between changes in antiindustry attitudes and the highest game level mastered. To account for the variation in the level of fact placement, we categorized gameplay into the following groups: "Did not play or played very little of Level 1," "Mastered Level 1Mastered Level 2," and "Mastered Level 3-Won the Game." Two additional items were used to assign a gameplay group: "I haven't played the game" and "I played for a few minutes and stopped." Cigarette smoking status was determined by one item that asked participants if they had ever tried cigarette smoking, even one or two puffs. ${ }^{30}$ This question was dichotomized for analysis into ever and never smokers.

The Anti-Tobacco Industry (ATI) Index measured attitudes about tobacco products and the tobacco industry. This index was developed by the authors to increase the conceptual understanding of the work. All tobacco-related attitudes and beliefs were subjected to a factor analysis to determine those final attributes that held together to form the Index. The final ATI Index included two items using a 7-point Likert scale, from extremely negative to extremely positive, to assess participant feelings about "tobacco companies" and "how tobacco companies market their products." Three additional items using a 5-point Likert scale, from strongly disagree to strongly agree, also assessed anti-tobacco industry sentiment ("Tobacco marketing is designed to manipulate young people," "Tobacco product development is designed to manipulate young people," and "Tobacco companies can't be trusted"). To address the variation in scale response categories ( 5 points versus 7 points), we standardized the scores to a scale of 10. Final scores represent the mean across the standardized items, with higher scores indicating more negativity toward the tobacco industry. Reliability for this index was good (Cronbach's alpha $=0.84)$.

\section{Analysis}

Post-stratification weights were used to produce nationally representative estimates. The study sample of participants with data at all three follow-up time points was used for this analysis (unweighted $n=689$; weighted $n=693$ ). Weighted univariate analyses produced descriptive statistics for key background characteristics and outcome measures at each data collection point (recruitment, 1 week, 1 month, and 3 months). Weighted bivariate analyses tested for associations between background characteristics and the outcome measures. Paired difference tests ( $t$ tests) were used to compare mean ATI Index scores at recruitment and 3 months by level mastered in the game. Weighted multivariable regression was used to examine the relationship of level mastered and the ATI Index after 
adjusting for control variables. All analyses were performed using Stata/SE version 13.1 software (www.statacorp.com).

\section{Results}

Table 2 highlights the characteristics of the study sample, which was almost evenly split in terms of gender (52 percent male and 48 percent female) and age (52 percent were 18-24 years of age; 48 percent were 13-17 years of age). The majority of the sample was white, non-Hispanic (60 percent), with 14 percent black, non-Hispanic, 8 percent other, nonHispanic, and 18 percent Hispanic. At baseline, 58 percent of the sample had never tried cigarettes.

The mean ATI Index score increased from 7.5 at recruitment to 8.0 at the 3-month follow-up (Fig. 3) for participants who beat Level 3 or won the game. Although there is no difference between ATI Index score at recruitment and at 3 months for those participants who "Did not play or played very little of Level 1" $(P=0.851)$, statistically significant differences in ATI Index attitudes were found for both those respondents who mastered Level 1 and Level 2 and those who mastered Level 3 or won the game $(P=0.000)$. Looking at both groups who played the game, the ATI Index score at recruitment rose from 7.5 (beat Level 3 or won the game) and 7.7 (beat Level 1 or 2) to 8.0 for either group at 3 months. Effect sizes for the period from recruitment to 3 months

\section{Table 2. Demographic and Background Characteristics of the Study Sample $(\mathrm{N}=693$, WeIGHTED $)$}

\begin{tabular}{lc}
\hline & $\begin{array}{c}\text { For cases with } \\
\text { data at three time } \\
\text { points after } \\
\text { recruitment } \\
(\mathrm{n}=693)\end{array}$ \\
Demographic characteristic & \\
\hline Age group (years) & 48.4 \\
13-17 & 51.6 \\
18-24 & \\
Gender & 52.3 \\
Male & 47.7 \\
Female & 59.8 \\
Race & 14.2 \\
Non-Hispanic white & 7.8 \\
Non-Hispanic black & 18.2 \\
Other non-Hispanic & \\
Hispanic & 56.8 \\
Respondent's education level & 43.2 \\
Some HS or less & \\
Some college or more & 3.2 \\
Parents' highest education level & 13.9 \\
Less than HS diploma & 31.1 \\
HS graduate & 51.8 \\
Some college/associate's degree & \\
College graduate or higher & 58.2 \\
Ever cigarette user at recruitment & 1.5 \\
Never & \\
Ever & \\
Number of games played on & \\
phone or tablet in typical & \\
week [mean (SD)] & \\
\hline
\end{tabular}

Data are percentages unless indicated otherwise. HS, high school; SD, standard deviation. increased with increasing gameplay, indicating that there was a meaningful change in attitudes as participants increased length of gameplay (effect size $=-0.36)($ Table 3 ). Results of a multivariable model demonstrate that level mastered is a significant predictor of increases in the ATI Index score at 3 months, controlling for baseline ATI Index score, age, gender, and ever cigarette use $(P=0.000)$. A multivariable model was also run predicting ATI Index scores at the time point when highest level of gameplay was achieved, regardless of when a player reached this level (e.g., 1 week, 1 month, or 3 months). This model yielded very similar results, suggesting a cumulative and enduring effect regardless of when a player reached his or her highest level of gameplay.

\section{Discussion}

Integrating health-related messages within a gaming context provides a unique opportunity to improve message exposure, comprehension, and receptivity among a teen target audience. Although games now exceed motion pictures as the dominant form of media, ${ }^{31,32}$ evidence of the efficacy of games to promote healthy behaviors is scant, and only a few studies have used rigorous evaluation designs. ${ }^{7}$ One review of electronic media-based behavioral interventions found that only a handful of studies used rigorous methods to assess behavior change or related outcomes such as knowledge or attitude change. ${ }^{33}$ To our knowledge, this is the first study in the United States to evaluate whether exposure to tobaccorelated messages within a mobile game can help shift related knowledge, attitudes, and beliefs among youth and young adults. Using a single-group repeated-measures design, findings indicate that "Flavor Monsters" gameplay, which includes a variety of fact-based messages integrated into the game narrative, is associated with increasing negative attitudes about tobacco products and the tobacco industry over time. Although gameplay was not a significant predictor of lower levels of intention to smoke, players reporting antitobacco and ATI Index attitudes were found to have a lower likelihood of initiating tobacco use.

There are numerous reasons why the gaming context offers a unique opportunity for integrating health messages compared with other media-based health education approaches. Gameplay itself immerses the audience into the message delivery, creating extended conversations where characters can help explain the message, raise questions about the message, and continue the dialogue about the message in ways not possible within other media venues. Players become actively engaged in the story and the strategy of the game rather than a passive listener to a narrative. This can serve to increase the potential for comprehension of and receptivity to a message, while prompting a synergistic effect of longer and deeper game engagement. Studies suggest that immersion in a story narrative of a videogame can transport players to a "flow" state where they lose track of time and become deeply engaged. ${ }^{34,35}$ Our study findings of the association between gameplay and changes in attitudes provide support for engagement as a key variable in understanding the pathway through which video gameplay can serve to improve health outcomes. Future research needs to examine the associations among game variables, psychosocial mediating variables, and behavioral outcomes. ${ }^{1}$ 


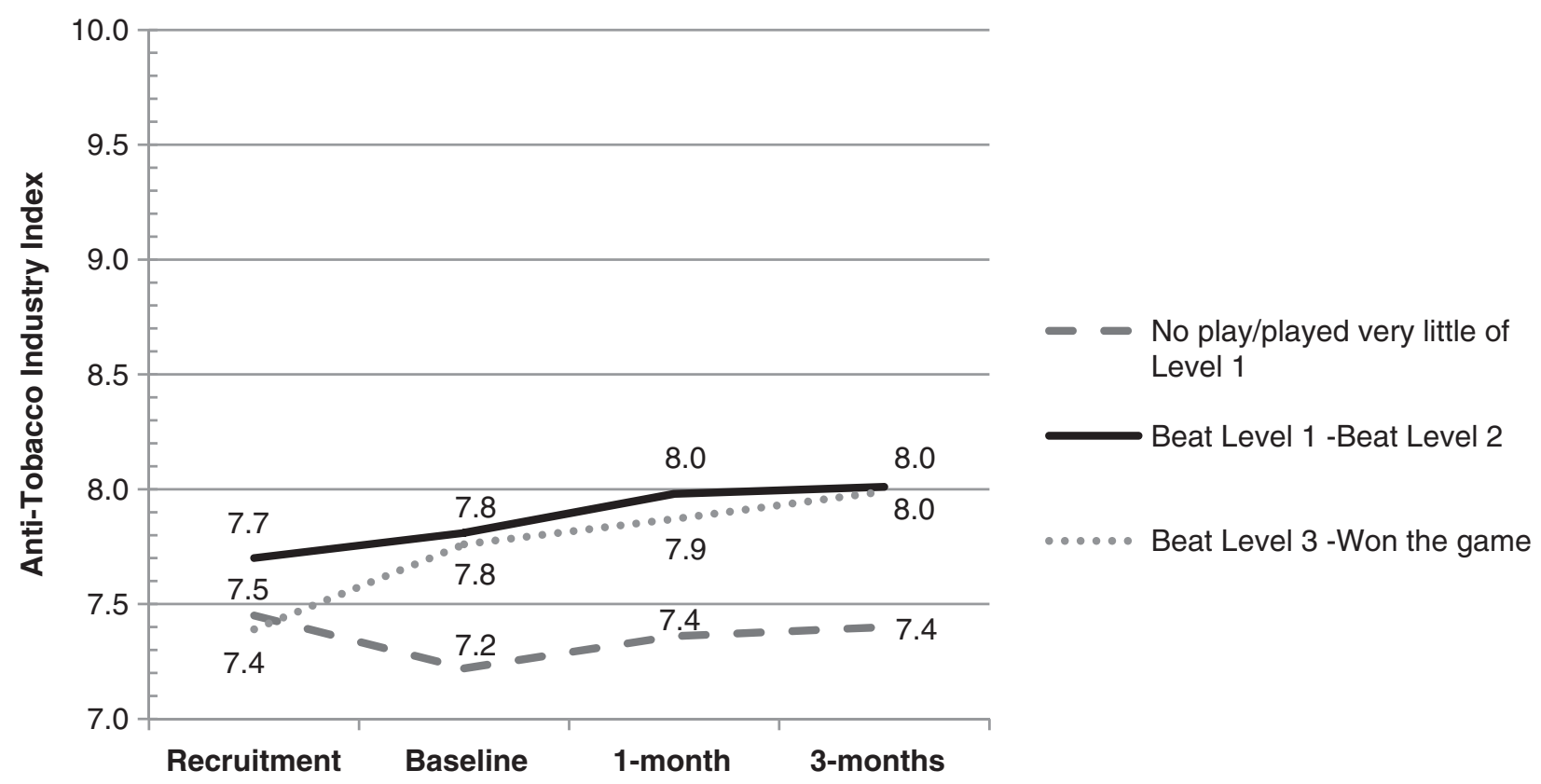

FIG. 3. Anti-Tobacco Industry Index by level of gameplay $(n=693)$.

\section{Strengths}

Strengths of this study include its initial phase, which provides support for integrating a high level of health-related content into mobile games despite concerns of lower receptivity and gameplay. The second phase of the evaluation uses a longitudinal study design that includes a large, diverse sample and multiple follow-up assessments over time. This naturalistic study design allowed for comparison of players with varying gameplay as well as non-players.

\section{Limitations}

Although numerous strengths exist, there are also some study limitations. First, self-reported gameplay was used to assess gameplay rather than more objective measures. Second, the study used a single-group repeated-measures design where some level of gameplay was required of each respondent, which limits our ability to generalize about realworld gameplay. Lastly, respondents were not randomized to a controlled dose of the intervention. However, this longitudinal naturalistic study did include variation of gameplay among its respondents. In addition, we conducted a bivariate attrition analysis comparing the study sample of participants who completed all three follow-up time points and those who dropped out before the third follow-up $(n=1934)$ on age, gender, race, ethnicity, education, ever cigarette use at recruitment, videogames played during the week, and the ATI Index. We found significant differences on two race categories (white and other, non-Hispanic) and the proportion of ever smokers at recruitment. However, none of the differences was enough to impact the results (differences did not exceed 6 percent), and no difference was observed between groups on the ATI Index at the first time point.

\section{Conclusions}

The popularity of mobile gaming among teens and young adults provides another important context for delivering health-related messages in an effort to promote healthy behavior. Given the extended period of time that players spend with story and character within this context, understanding how best to optimize message delivery while not impeding gameplay is key to maximizing the impact of such an intervention. Results from this longitudinal study indicate that anti-tobacco content can be successfully integrated within a mobile game to help increase anti-tobacco attitudes. Future research needs to continue to document the impact of health-related content within mobile games as well as examining the mechanisms through which these effects occur.

Table 3. Means and Effect Sizes for Anti-Tobacco Industry Index Scores By LeVels of Gameplay $(\mathrm{N}=693$, Weighted)

\begin{tabular}{lccrr}
\hline \multirow{2}{*}{ Gameplay } & \multicolumn{2}{c}{ Anti-Tobacco Industry Index [mean (SD)] } & & \\
\cline { 2 - 3 } & Recruitment & Wave 3 & P value & Effect size $^{\mathrm{a}}$ \\
\hline Did not play or played very little of Level 1 $(n=48)$ & $7.45(1.81)$ & $7.40(1.83)$ & 0.851 & 0.03 \\
Beat Level 1-Beat Level 2 $(n=322)$ & $7.70(1.70)$ & $8.01(1.63)$ & 0.000 & -0.18 \\
Beat Level 3 or won the game $(n=323)$ & $7.39(1.63)$ & $7.99(1.69)$ & 0.000 & -0.36 \\
\hline
\end{tabular}

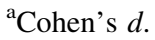

$\mathrm{SD}$, standard deviation. 


\section{Acknowledgments}

The authors would like to thank Christine Dela Rosa, Crux Research, and Sabertooth for their contributions to the design of the "Flavor Monsters" game and/or the evaluation.

\section{Author Disclosure Statement}

No competing financial interests exist.

\section{References}

1. Baranowski T, Baranowski J, Thompson D, Buday R. Behavioral science in video games for children's diet and physical activity change. J Diabetes Sci Technol 2011; 5:229-233.

2. Lu AS, Baranowski T, Thompson D, Buday R. Story immersion of videogames for youth health promotion: A review of literature. Games Health J 2012; 1:199-204.

3. Biddiss E, Irwin J. Active video games to promote physical activity in children and youth. Arch Pediatr Adolesc Med 2010; 164:664-672.

4. Peng W, Lin JH, Crouse J. Is playing exergames really exercising? A meta-analysis of energy expenditure in active video games. Cyberpsychol Behav Soc Netw 2011; 14:681-688.

5. Zamzee. https://www.zamzee.com/ (accessed May 29, 2013).

6. Zombies, Run! 2. https://www.zombiesrungame.com/ (accessed May 29, 2013).

7. Kato PM. Evaluating efficacy and validating games for health. Games Health J 2012; 1:74-76.

8. Hieftje K, Rosenthal MS, Camenga DR, et al. A qualitative study to inform the development of a videogame for adolescent human immunodeficiency virus prevention. Games Health J 2012; 1:294-298.

9. Jivehealth. http://jivehealth.com/ (accessed May 29, 2013).

10. Replay: Finding Zoe. www.metrac.org/replay/en/index.html (accessed May 29, 2013).

11. Lenhart A, Kahne J, Middaugh E, et al. Teens, Video Games, and Civics. The Pew Research Center. 2008. www .pewinternet.org/2008/09/16/teens-video-games-and-civics/ (accessed January 5, 2015).

12. Lomas N. Smartphones \& Tablets to be Primary Screen for Gamers, Says Analyst, Powering 64BN+ Games Downloads by 2017 (3X 2012 Figure). TechCrunch2013. http:// techcrunch.com/2013/04/25/juniper-games-downloads-forecast/ (accessed January 5, 2015).

13. Mokdad AH, Marks JS, Stroup DF, Gerberding JL. Actual causes of death in the United States, 2000. JAMA 2004; 291:1238-1245.

14. Danaei G, Ding EL, Mozaffarian D, et al. The preventable causes of death in the United States: Comparative risk assessment of dietary, lifestyle, and metabolic risk factors. PLoS Med 2009; 6:e1000058.

15. Tingen MS, Gramling LF, Bennett G, et al. A pilot study of preadolescents using focus groups to evaluate appeal of a video-based smoking prevention strategy. J Addict Nurs 1997; 9:118-124.

16. Lit 2 Quit! http://lit2quit.wordpress.com/ (accessed May 29, 2013).

17. kwit: Quit smoking is a game! http://kwit.fr/ (accessed May 29, 2013).

18. Khazaal Y, Chatton A, Prezzemolo R, et al. Impact of a board-game approach on current smokers: A randomized controlled trial. Subst Abuse Treat Prev Policy 2013; 8:3.

19. Girard B, Turcotte V, Bouchard S, Girard B. Crushing virtual cigarettes reduces tobacco addiction and treatment discontinuation. Cyberpsychol Behav 2009; 12:477-483.
20. Ip P, Lam TH, Chan SS, et al. Use of Internet viral marketing to promote smoke-free lifestyles among Chinese adolescents. PloS One 2014; 9:e99082.

21. U. S. Department of Health and Human Services. Preventing Tobacco Use Among Youth and Young Adults: A Report of the Surgeon General. Atlanta: Office on Smoking and Health, National Center for Chronic Disease Prevention and Health Promotion, Centers for Disease Control and Prevention; 2012.

22. Ling PM, Glantz SA. Why and how the tobacco industry sells cigarettes to young adults: Evidence from industry documents. Am J Public Health 2002; 92:9.

23. Advertising Age. Top Ad Campaigns of the 21st Century. 2014. http://adage.com/lp/top15/\#truth (accessed January 5, 2015).

24. Evans WD, Wasserman J, Bertolotti E, Martino S. Branding behavior: The strategy behind the truth campaign. Soc Market Q 2002; 8:17-29.

25. Farrelly MC, Healton CG, Davis KC, et al. Getting to the truth: Evaluating national tobacco countermarketing campaigns. Am J Public Health 2002; 92:901-907.

26. truth. Flavor Monsters. www.thetruth.com/games/play/flavormonsters/ (accessed May 29, 2013).

27. Google. Google Play: Flavor Monsters. 2015. https://play .google.com/store/apps/details?id = com.americanlegacy .flavormonsters\&hl =en (accessed January 20, 2015).

28. Apple Inc. iTunes Preview: Flavor Monsters. 2015. https:// itunes.apple.com/us/app/flavor-monsters/id546157164?mt = 8 (accessed January 20, 2015).

29. Buday R, Baranowski T, Thompson D. Fun and games and boredom. Games Health J 2012; 1:257-261.

30. Centers for Disease Control and Prevention. National Youth Tobacco Survey (NYTS) 2014 Questionnaire. 2014. www.cdc.gov/TOBACCO/data_statistics/surveys/NYTS/ index.htm (accessed January 5, 2015).

31. Chatfield T. Videogames Now Outperform Hollywood Movies. The Guardian. 2009. www.theguardian.com/ technology/gamesblog/2009/sep/27/videogames-hollywood (accessed January 5, 2015).

32. Correa C. Why Video Games Are More Addictive And Bigger Than Movies Will Ever Be. Forbes. 2013. www .forbes.com/sites/christophercorrea/2013/04/11/why-videogames-are-addictive-and-bigger-than-movies-will-ever-be/ (accessed January 5, 2015).

33. Hieftje K, Edelman EJ, Camenga DR, Fiellin LE. Electronic media-based health interventions promoting behavior change in youth: A systematic review. JAMA Pediatr 2013; 167:574-580.

34. Read JL, Shortell SM. Interactive games to promote behavior change in prevention and treatment. JAMA 2011; 305:1704-1705.

35. Hull DC, Williams GA, Griffiths MD. Video game characteristics, happiness and flow as predictors of addiction among video game players: A pilot study. J Behav Addict 2013; 2:145-152.

Address correspondence to:

Jessica M. Rath, PhD, MPH

Department of Evaluation Science and Research Legacy 1724 Massachusetts Avenue, NW Washington, DC 20036

E-mail: jrath@legacyforhealth.org 